Bertsch, Markus, Wegner, Reinhard, Landschaft am "Scheidepunkt » : Evolutionen einer Gattung in Kunsttheorie, Kunstschaffen und Literatur um 1800

\title{
François Walter
}

\section{OpenEdition}

Édition électronique

URL : http://journals.openedition.org/ifha/6629

DOI : $10.4000 /$ ifha.6629

ISSN : 2198-8943

Éditeur

IFRA - Institut franco-allemand (sciences historiques et sociales)

\section{Référence électronique}

François Walter, «Bertsch, Markus, Wegner, Reinhard, Landschaft am «Scheidepunkt »: Evolutionen einer Gattung in Kunsttheorie, Kunstschaffen und Literatur um 1800 », Revue de I'IFHA [En ligne], Date de recension, mis en ligne le 01 janvier 2011, consulté le 22 septembre 2020. URL : http:// journals.openedition.org/ifha/6629; DOI : https://doi.org/10.4000/ifha.6629

Ce document a été généré automatiquement le 22 septembre 2020.

(CIFHA 


\title{
Bertsch, Markus, Wegner, Reinhard, Landschaft am "Scheidepunkt » : Evolutionen einer Gattung in Kunsttheorie, Kunstschaffen und Literatur um 1800
}

\author{
François Walter
}

1 Issu du colloque éponyme organisé en 2006 à Iéna, ce volume publie 17 communications très pointues d'auteurs, historiens de l'art en grande majorité, mais aussi spécialistes de littérature allemande et de musicologie. Le point de départ de la réflexion repose sur un constat : vers 1800, le paysage est au cœur du discours esthétique. En Allemagne, plus particulièrement, on a commencé par traduire des écrits étrangers puis, dès 1774 (date de parution de la théorie des beaux-arts de Sulzer), à produire une littérature théorique sur le paysage. Ce courant accompagne le mouvement européen qui fait de la peinture de paysage un genre autonome à la fin du XVIIIe siècle. L'effort théorique est sans doute lié au besoin de le valoriser à côté de la peinture d'histoire qui demeure, du point de vue académique, le genre noble par excellence. Pour les lecteurs de langue française, le livre d'E. Décultot sur un thème similaire, paru en 1996, donne les orientations nécessaires. Cette spécialiste signe d'ailleurs l'article d'ouverture de ce colloque.

2 À défaut de reprendre les uns après les autres les différents articles, cette présentation se bornera à mettre en évidence quelques thématiques particulièrement stimulantes par leurs connexions possibles avec l'histoire culturelle, en laissant délibérément de côté les réflexions sur les questions stylistiques et formelles. Disons d'emblée, que l'histoire sociale et culturelle n'est pas la préoccupation majeure, on s'en doute, des auteurs ici réunis, observation qui n'enlève rien à la pertinence de leurs analyses dans leur discipline. 
Plusieurs contributions analysent les rapports entre le paysage littéraire et des lieux concrets. L'Élysée de Clarens et Ermenonville sont mentionnés, le jardin paysage figurant un espace de projection du texte littéraire. Avec la musique, la littérature joue un rôle médiateur pour l'idylle. Les poèmes de Geßner ont ainsi leurs répondants dans la musique baroque (chez Telemann notamment). Le lecteur trouvera aussi quelques pages utiles sur des figures emblématiques de la littérature comme le promeneur (chez Goethe ou Klopstock). Des analyses similaires sont esquissées pour la peinture paysagère romantique allemande (Caspar David Friedrich). Le personnage mythique du barde Ossian est bien sûr présent comme le motif du moine (chez Friedrich et le nazaréen Ferdinand Olivier).

4 L'actualisation des courants anciens de la peinture allemande ou des primitifs italiens (sur les toiles de Josef Anton Koch) est bien contextualisée. Le traitement pictural de scènes bibliques par Philipp Otto Runge est astucieusement mis en relation avec la publication des descriptions de l'Égypte qui suivent l'expédition française. Moins connue, l'inspiration paysagère des peintres dits nazaréens (comme Friedrich Overbeck) est évoquée par plusieurs articles. Pour les historiens, on mentionnera une belle analyse de M. Maurer portant sur la découverte du paysage des Wales (Pays de Galles) par les voyageurs allemands vers 1784 . En effet, c'est d'habitude le regard des Anglais transposant en Europe leur regard des montagnes cambriennes qui a focalisé l'attention. Ici, on voit les Allemands découvrir la «barbarie » de populations que l'on compare aux civilisés du continent. En outre, le schème anticipatif qui médiatise le regard est celui des Alpes suisses. Pour le peinte Carus (en 1844), les montagnes anglaises deviennent une sorte de condensé pittoresque des Alpes, un seul rocher présentant en petit ce qu'une montagne incarne en grand. Le choix très resserré de la chronologie dans ce livre (1780 aux premières décennies du XIXe siècle) empêche sans doute des ouvertures plus audacieuses encore.

François Walter (université de Genève) 